\title{
Testing a theory of aircraft noise annoyance: A structural equation analysis
}

\author{
Maarten Kroesen, ${ }^{\text {a) }}$ Eric J. E. Molin, and Bert van Wee \\ Faculty of Technology, Policy and Management, Delft University of Technology, P.O. Box 5015, \\ 2600 GA Delft, The Netherlands
}

(Received 2 August 2007; revised 18 March 2008; accepted 6 April 2008)

\begin{abstract}
Previous research has stressed the relevance of nonacoustical factors in the perception of aircraft noise. However, it is largely empirically driven and lacks a sound theoretical basis. In this paper, a theoretical model which explains noise annoyance based on the psychological stress theory is empirically tested. The model is estimated by applying structural equation modeling based on data from residents living in the vicinity of Amsterdam Airport Schiphol in The Netherlands. The model provides a good model fit and indicates that concern about the negative health effects of noise and pollution, perceived disturbance, and perceived control and coping capacity are the most important variables that explain noise annoyance. Furthermore, the model provides evidence for the existence of two reciprocal relationships between (1) perceived disturbance and noise annoyance and (2) perceived control and coping capacity and noise annoyance. Lastly, the model yielded two unexpected results. Firstly, the variables noise sensitivity and fear related to the noise source were unable to explain additional variance in the endogenous variables of the model and were therefore excluded from the model. And secondly, the size of the total effect of noise exposure on noise annoyance was relatively small. The paper concludes with some recommended directions for further research. (C) 2008 Acoustical Society of America. [DOI: 10.1121/1.2916589]
\end{abstract}

PACS number(s): 43.50.Rq, 43.50.Qp, 43.50.Lj [BSF]

Pages: $4250-4260$

\section{INTRODUCTION}

The global aviation sector has rapidly developed since the beginning of the 1960s. Air travel has grown due to numerous factors such as economic and demographic growth, decreasing market prices, globalization, increasing quality, the introduction of the hub-and-spoke concept, and liberalizing measures. With this growth, the negative externalities of the aviation market have also become more evident: noise, local and global air pollution, and decreasing external safety.

The noise policies adopted by national governments in relation to major airports mainly focus on reducing the level of noise exposure and the number of people who are exposed. However, there is no one-on-one relationship between noise exposure and noise annoyance. Based on 39 empirical studies, Job (1988) concluded that the correlation coefficient for group data (aggregate models) is 0.82 (standard deviation of 0.14 ) and for individual data 0.42 (standard deviation of 0.12 ). This means that in the latter case, only $18 \%$ of the variance in noise annoyance is explained by noise exposure. ${ }^{1}$ One explanation for this weak relationship is that factors other than the level of noise exposure, the so-called nonacoustical factors, influence noise annoyance. Guski (1999) concluded that approximately one-third of the variation in noise annoyance can be explained by acoustical factors (e.g., the sound level, peak levels, sound spectrum, and number of noise events) and a second third by nonacoustical factors. The last third can either be attributed to measurement errors (which decreases the proportion of explained variance in the

\footnotetext{
a)Electronic mail: m.kroesen@tudelft.nl.
}

dependent variables), the presence of yet unknown factors which influence noise annoyance, or stochastic variation related to idiosyncrasies of individuals.

Past studies that investigated relevant nonacoustical factors, however, have two major shortcomings. Firstly, the research can be characterized as highly inductive, which generally means that it lacks a sound theoretical basis (Taylor, 1984). As Taylor noted (1984) (p. 245), "many of the models which are tested by using path analysis are exploratory. As such, they probably do not adequately represent the processes leading to the outcome in question (e.g., noise annoyance). In such cases, causal claims stand on weak ground indeed and sensibly are best avoided." In addition, although not mentioned by Taylor, the lack of elementary understanding related to the topic of noise annoyance can result in misspecification of the statistical model and hence even lead to false inferences related to the effect sizes of relevant variables.

Secondly, the practical relevance and significance of nonacoustical factors in relation to noise annoyance are often based on correlational analysis or multiple regression analysis. Both these methods have severe deficiencies in modeling noise annoyance. As Alexandre (1976) has shown, the results of correlational analysis can be misinterpreted since the effect of the factor under investigation is not controlled for noise exposure or other factors. In addition, the direction of causation remains uncertain. Of the three commonly accepted conditions needed to qualify something as a causal relationship, i.e., time precedence, nonspuriousness, and simple association, only the last one is satisfied. The result is that the relative importance of different factors may be under-or overestimated. With multiple regression analysis, 
the effects of different nonacoustical factors can be controlled for noise exposure and other factors. However, this method is not suited to model indirect and reciprocal effects. Without being able to include these relationships, the model may contain serious misspecifications and hence lead to false inferences about the parameter estimates associated with different causes of annoyance.

This paper aims to overcome these shortcomings by developing and estimating a causal model of aircraft noise annoyance based on theory which includes nonacoustical and acoustical variables. The model is based on a conceptualization of noise annoyance by Stallen (1999) which is rooted in the psychological stress theory of Lazarus (1966). To the authors' knowledge, this is, as of yet, the only theory that gives an explanation for noise annoyance. Since the conceptual model, besides direct relationships, includes indirect and reciprocal relationships between variables, structural equation modeling (SEM) is applied to estimate the model. This method is especially suitable to model these complex causal relationships (Bollen, 1989). An additional advantage of SEM is that it can take measurement errors into account, which results in less bias in the estimated coefficients and potentially larger portions of explained variance. Data to estimate the model are gathered through a survey among residents living inside the 45 DENL $^{2}$ contour around Amsterdam Airport Schiphol (AAS), the largest airport in The Netherlands.

The structure of this paper is as follows. Section II discusses the causal model to explain aircraft noise annoyance which is based on the psychological stress theory. The third section presents the research approach and data gathering procedure. Section IV discusses the model results. The last section presents the main conclusions and concludes with some reflective remarks and related recommended directions for further research.

\section{TOWARD A CAUSAL MODEL OF NOISE ANNOYANCE}

This section first discusses the definition of noise annoyance, after which the model of Stallen (1999) is presented, which forms the core of the noise annoyance model to be tested in this paper. Following this, relevant acoustical and nonacoustical factors are identified and the constructed causal model is elaborated.

Based on a survey among experts, Guski et al. (1999) concluded that noise annoyance is a multifaceted concept, which covers immediate behavioral noise aspects, such as disturbance and interference with activities, and long-term evaluative aspects such as nuisance, unpleasantness, and getting on one's nerves. Although the two components of noise annoyance, i.e., disturbance and nuisance, can be theoretically distinguished, Guski (1999) noted that it is unknown how the integration of short-term experiences and long-term evaluation related to the acoustic environment takes place. It is unknown whether, for example, the most severe disturbances are remembered or whether a respondent averages all the disturbances he or she can remember. Guski et al. (1999 p. 525) also emphasised that noise annoyance is not just reflecting acoustic characteristics: "noise annoyance de-

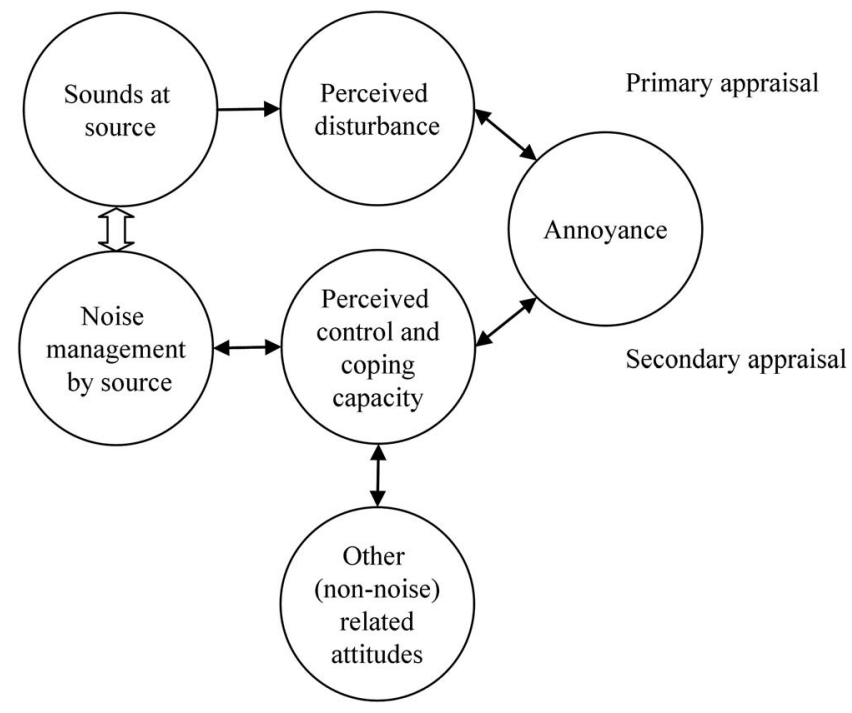

FIG. 1. The conceptual model of Stallen (1999) used to explain noise annoyance. Noise annoyance is defined as a form of psychological stress, which is determined by the perceived impact of a stressor and the perceived resources to cope with this stressor.

scribes a situation between an acoustic situation and a person who is forced by noise to do things he or she does not want to do, who cognitively and emotionally evaluates this situation and feels partly helpless." This statement is in line with Stallen's (1999) definition of noise annoyance as a form of psychological stress, which constitutes the fundamental idea behind his conceptual model of noise annoyance and is discussed below.

Different models have been developed that aim to provide insight into the processes that result in noise annoyance (Taylor, 1984; Job, 1996; Guski, 1999). However, all these models are developed based on empirical evidence related to previously found correlations between noise annoyance and other variables. Since these associations between noise annoyance and nonacoustical factors have been found in an exploratory manner, these models are based on implicit theory rather than on a predefined theory of noise annoyance. In his application of the psychological stress theory of Lazarus (1966) on the phenomenon noise annoyance, Stallen (1999) developed an explicit theoretical framework for describing the process of noise annoyance. Empirical research by Lazarus (1966) and others has revealed two major determinants of stress: perceived threat and perceived control. Stallen (1999) argued that the perceived disturbance (i.e., short-term or immediate annoyance) and the perceived threat basically form equal concepts. Subsequently, noise annoyance as a form of psychological stress is determined by the extent to which a person perceives a threat (i.e., perceived disturbance) and the possibilities or resources that a person has with which to face this threat (i.e., perceived control) (Stallen, 1999). Stallen's conceptual model is presented in Fig. 1. The presented model is a simplified and slightly adapted version of the original model (i.e., perceived control and coping capacity are treated as one factor).

The level of perceived disturbance, also called the primary appraisal, is a person's evaluation of the impact of the threat or harm in relation to his or her well being. The acous- 
tic situation to which one is exposed is considered the main determinant of this evaluation. After a threat or harm is recognized, a process of secondary appraisal is triggered. Within this process, the resources to face the threat are evaluated. One potential resource results from the relationship one has with the noise source. If this relationship is good, one is better able to handle the impact of the stressor. However, in the words of Maris et al. (2007) (p. 2001): "if the exposed has little control over the source, or little trust in the source, the perceived coping resources will be reduced and psychological stress will arise." Next to the noise management by the source, other non-noise related attitudes can be considered as potential coping resources. In this respect, Stallen (1999) mentioned nonacoustical factors such as beliefs about the importance of the noise source and annoyance with nonnoise impacts of the noise source, which were identified by Fields' extensive review as supported by sufficient evidence (Fields, 1993).

Based on his model, Stallen (1999) argued that if the perceived threat (i.e., noise) is larger than the perceived resources to face the threat (i.e., perceived control and coping capacity), psychological stress (i.e., noise annoyance) will arise. In addition, even though the perceived disturbance may be very high, no noise annoyance will arise if there are sufficient coping resources. Lastly, since the process of coping is in a constant flux, the theoretical framework includes multiple reciprocal relationships between variables.

To further extend the conceptual model of aircraft noise annoyance, relevant acoustical and nonacoustical factors that play a significant role in the noise-reaction relationship are supplemented. These variables are identified based on the results of past studies. In Table I, the variables found by Lercher (1996) and Guski (1999), based on reviews of studies that investigated the effects of personal, social, and contextual variables on annoyance, are enumerated. The current overview is complemented with studies by Miedema and Vos (1999) and Fields (1993) who assessed the influence of (non)acoustical factors on annoyance via metaanalyses.

To limit the number of variables in order to avoid problems in the data collection phase only the variables of which the evidence is sufficiently present as indicated by the cited authors are included in the extended model of noise annoyance. An additional criterion for inclusion is that a theoretical notion must exist that explains how each variable influences one or more dependent variables (i.e., the "mechanism of causation") in the conceptual model of Stallen (Fig. 1). Such theoretical notions could not be given for neighborhood satisfaction (for which it is more likely to be a dependent variable itself), education, occupational/social status, and household size. In addition, since these latter three variables have only a small effect size on noise annoyance, causing an estimated extra annoyance equivalent to $2 \mathrm{~dB}$ day-night level or less (Miedema and Vos, 1999), their exclusion will not substantially affect the model. In addition, the variable "change in noise environment" is omitted. The reason for this is that the structural equation modeling approach assumes that an estimated model and hence the "process of noise annoyance" are in a stable state. The fact that the doseresponse function, which predicts the percentage of highly annoyed people for varying levels of noise exposure, has not significantly changed for nearly a decade for residents living around AAS (RIVM and RIGO, 2006), suggests that this assumption holds in our study. ${ }^{3}$ The exclusion of noise insulation will be explained in the next section.

The relevant acoustical and nonacoustical variables (Table I) and the conceptual model of Stallen (1999) (Fig. 1) are combined in an extended model of noise annoyance, which is constructed as follows. In line with Stallen's framework, noise annoyance is assumed to have two determinants, the perceived level of disturbance and the perceived level of control and coping capacity, which have a positive and a negative effect on noise annoyance, respectively.

The level of perceived disturbance is assumed to be positively influenced by the level of noise exposure and noise sensitivity. In turn, since noise sensitivity has been shown to be significantly associated with age and length of residence in noisy areas (for a brief review, see Van Kamp et $a l ., 2004)$, this variable is assumed to be influenced by these variables. Although on the balance of existing evidence, it is concluded that this length of residence in noisy areas has no significant relationship with annoyance (Table I; Fields, 1993), it is plausible that length of stay indirectly influences annoyance through the noise sensitivity of a person.

The perceived level of control and coping capacity are assumed to be directly influenced by the negative attitude toward noise source authorities and the noise policy (i.e., the noise management by the source) and by other nonacoustical variables (i.e., non-noise related attitudes). Dependent on whether the respective variables "add" or "extract" coping potential, the sign of the hypothesised relationship is either positive or negative. In addition, the effects of nonacoustical variables on the perceived level of control and coping capacity are assumed to be mediated by the negative attitude toward noise source authorities and the noise policy. For all included nonacoustical variables, the assumption that these variables can deteriorate or improve the relationship between residents around the airport and the noise source authorities (i.e., the government and airport operators) is plausible. Therefore, the hypothesis that these factors influence the attitude toward the source authorities and the policies they adopt to control the noise will also be tested. Hence, it is hypothesized that the nonacoustical variables directly influence the perceived level of control and coping capacity as well as indirectly via the negative attitude toward noise source authorities and the noise management. For example, a strong belief that noise can be prevented can directly lead to a perceived loss of coping potential (i.e., a lack of control over the situation) as well as increase distrust in the authorities and the adopted noise policy through which the coping potential also decreases.

Since, in the words of Stallen (1999), (p. 77), coping is a process with information flowing back and forth (i.e., the process of coping can be seen as a constant reappraisal of the person-environment relationship), Stallen's framework included several reciprocal relationships. In relation to the extended model described here, it is assumed that the perceived level of disturbance not only influences noise annoyance but also noise annoyance in turn, influences the degree of per- 
TABLE I. Overview of acoustical and nonacoustical variables.

\begin{tabular}{|c|c|c|c|}
\hline Nonacoustical variables & $\begin{array}{l}\text { Sufficient } \\
\text { evidence }\end{array}$ & Reference $^{c}$ & $\begin{array}{l}\text { Included in the } \\
\text { extended model }\end{array}$ \\
\hline Critical tendencies ${ }^{\mathrm{a}}$ & & 1 & \\
\hline Negative affectivity & & 1 & \\
\hline Neuroticism/extraversion & & 1 & \\
\hline Locus of control & & 1 & \\
\hline Type $\mathrm{A} / \mathrm{B}^{\mathrm{b}}$ & & 1 & \\
\hline Noncomplaining attitude & & 1 & \\
\hline Noise sensitivity & $\cdots$ & $1,2,3,4$ & $\cdots$ \\
\hline Misfeasance in relation to source authorities & $\cdots$ & 1,2 & $\cdots$ \\
\hline Preventability beliefs & $\cdots$ & 1,4 & $\cdots$ \\
\hline Fear of noise source & $\cdots$ & $1,2,3,4$ & $\cdots$ \\
\hline Concern about negative health effects of noise & $\cdots$ & 1,2 & $\cdots$ \\
\hline Social evaluation of the source/attitude towards the source & $\cdots$ & $1,2,4$ & $\cdots$ \\
\hline Interference with activities (i.e. activity disturbances) & $\cdots$ & 1,2 & $\cdots$ \\
\hline $\begin{array}{l}\text { Controllability/predictability/adaptability in relation to noise } \\
\text { situation }\end{array}$ & $\cdots$ & 1 & $\cdots$ \\
\hline Annoyance in relation to non-noise effects (odour, vibrations) & $\cdots$ & 1,4 & $\cdots$ \\
\hline Neighborhood satisfaction & $\cdots$ & 1 & \\
\hline Home ownership/concern about property devaluation & $\cdots$ & $1,3,4$ & $\cdots$ \\
\hline Aesthetic appearance of site & & 1 & \\
\hline Negative expectations related to future development of noise & $\cdots$ & 2 & $\cdots$ \\
\hline Coping capacity & $\cdots$ & 1,2 & $\cdots$ \\
\hline Gender & & 3,4 & \\
\hline Age & $\cdots$ & 3 & $\cdots$ \\
\hline Education & $\cdots$ & 3 & \\
\hline Income & & 4 & \\
\hline Occupational/social status & $\cdots$ & 3 & \\
\hline Household size & $\cdots$ & 3 & \\
\hline $\begin{array}{l}\text { Personal evaluation of the source/dependency on the noise } \\
\text { source }\end{array}$ & $\cdots$ & $2,3,4$ & $\cdots$ \\
\hline Length of residence/length of residence in noisy areas & & 4 & $\cdots$ \\
\hline \multicolumn{4}{|l|}{ Acoustical variables } \\
\hline Noise exposure (e.g., DENL) & $\cdots$ & 5 & $\cdots$ \\
\hline History of noise exposure levels/exposure time & & $1,2,4$ & \\
\hline Change in noise environment/time since change & $\cdots$ & 1,4 & \\
\hline Home type and design/rooms facing noise source & & 1,4 & \\
\hline Noise insulation & $\cdots$ & 4 & \\
\hline Background noise level & & 4 & \\
\hline
\end{tabular}

${ }^{a}$ The general tendency of individuals to express critical or negative judgments.

${ }^{\mathrm{b}}$ Type A personality is a set of characteristics that includes being impatient, excessively time conscious, insecure about one's status, highly competitive, hostile and aggressive, and incapable of relaxation (Friedman and Rosenman, 1974).

${ }^{c}$ References: $1=$ Lercher (1996) and references presented in this paper; $2=$ Guski (1999) and references presented in this paper; 3=Miedema and Vos (1999); 4=Fields (1993); 5=Job (1988).

ceived disturbance. The hypothesis is that an annoyed person is more prone to be frequently disturbed by the acoustic environment. A second reciprocal relationship is assumed to be present between noise annoyance and the perceived level of control and coping capacity. It is hypothesized that more stress (annoyance) increases the incentive for people to find direct or indirect ways to cope with the stressor. In other words, it is assumed that being in a state of "high annoyance" leads people to adopt cognitive or direct coping strategies to reduce their level of stress. Glass and Singer (1972) used the term adaptation to characterize this process. They argue that since humans can rely on cognitive processes to achieve adaptation, they have a large variety of adaptive mechanisms at their disposal to protect themselves (Glass and Singer, 1972). ${ }^{4}$

It needs to be noted that the reciprocity assumed between noise annoyance and perceived disturbance is purely cognitive, while the path from perceived control and coping capacity toward noise annoyance is both cognitive (i.e., including latent mental processes such as emotional regulation) and behavioral (i.e., including direct coping strategies such as closing a window). Hence, to correctly model this process would require inclusion of such behavioral strategies in a feedback loop from noise annoyance to perceived control and coping capacity, in addition to the direct feedback loop 


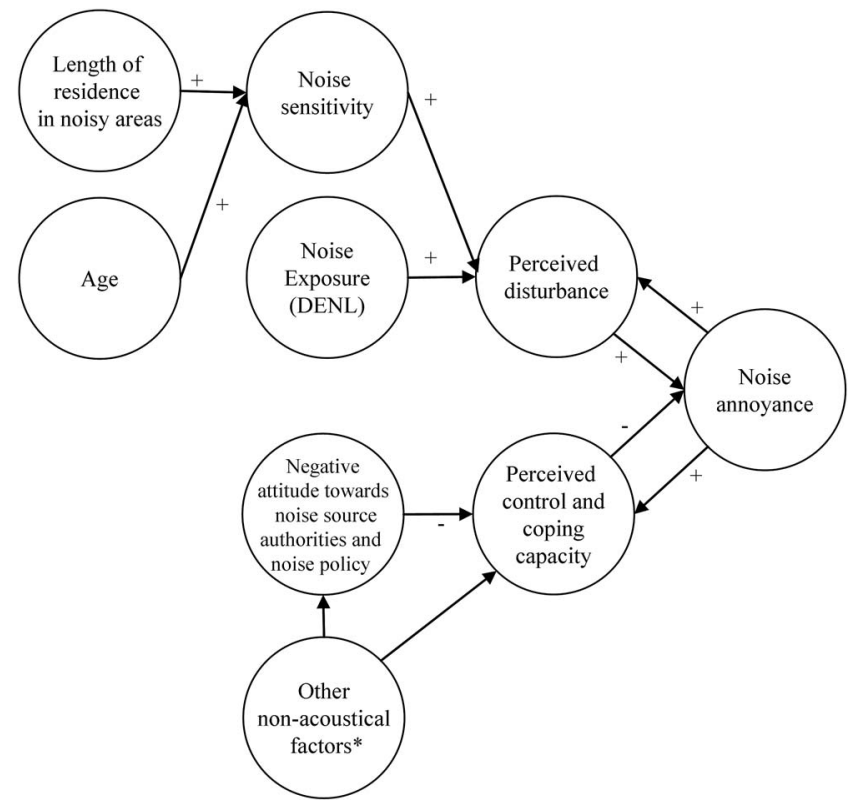

FIG. 2. The developed causal model of aircraft noise annoyance. Included nonacoustical factors are the following. (1). Belief noise can be prevented $(-)$. (2). Positive social evaluation of the noise source (+). (3) Negative expectations related to noise development $(-)$. (4). Personal dependency on noise source (+). (5) Concern about negative health effects of noise and pollution (-). (6) Annoyance by non-noise effects (i.e., vibrations, dust, and odor) (-). (7) Fear related to noise source (-) and (8) Concern about property devaluation $(-)$. Note that the sign in the parentheses relates to the hypothesized relationship of the respective variable with perceived control and coping capacity (the sign of the assumed relationship with the negative attitude toward noise source authorities and the noise policy is the opposite of this sign).

which represents mental coping. However, by considering the range of different behavioral coping strategies, the fact that such strategies can have both positive and negative outcomes, and the fact that such behavioral responses have other antecedents next to noise annoyance (which would also needed to be taken into account), inclusion of this behavior in the present model would be too complex to achieve. Therefore, this additional indirect feedback loop is not explicitly modeled but assumed to be sufficiently captured by the direct feedback loop. Hence, it is assumed that these behavioral coping strategies have a net positive effect.

The extended causal model is depicted in Fig. 2.

\section{RESEARCH APPROACH}

\section{A. Sample}

The extended model depicted in Fig. 2 is parametrized in the form of structural equation model. Data to estimate this model were gathered via a survey among residents living inside 45 DENL contour around Amsterdam Airport Schiphol (AAS) in The Netherlands. Approximately 1.5 $\times 10^{6}$ people live within this area. The lower limit of 45 DENL is chosen to physically constrain the size of the geographic survey area. Approximately $85 \%$ of all people around AAS who are being highly annoyed by aircraft noise live within this contour (RIVM and RIGO, 2006). Highly annoyed in this respect is defined according to the convention definition of a score of 72 or higher on a scale from 0 (no annoyance at all) to 100 (very high annoyance) (e.g., Miedema and Vos, 1998). The level of noise exposure in the dataset $^{5}$ ranges from 45 DENL through 58 DENL (only $0.8 \%$ of the people around AAS exposed to 45 DENL or more are exposed to higher levels than 58 DENL). Since only residents who are exposed to $60 \mathrm{DENL}$ or more are eligible to receive noise insulation, and because the upper limit of the level of noise exposure in the sample is 58 DENL, the effects of this variable could not be estimated and it was therefore excluded from further analysis.

From the chosen geographical survey area, a random sample of dwellings was selected. Per selected dwelling, one resident was approached via a letter (delivered at the home address) that invited him or her to fill in an online questionnaire. The letter contained the URL of the website where this questionnaire could be reached. The survey was conducted at the beginning of April 2006. Although issues surrounding Airport Schiphol are highly controversial (i.e., expansion, noise pollution, and emissions) (Van Eeten, 2001), there was no public debate or explicit media attention at the time of data collection or in the preceding months.

Considering the large amount of variables and to avoid problems with multicollinearity and/or deviations from normality, the sample size had to be sufficiently large (at least more than 400). Based on an expected response ratio of $10 \%$, 7000 residents were approached. With 646 useable responses, the actual response ratio was $9.2 \%$. The completion ratio was $91.8 \%$, which indicates that there was no serious matter of questionnaire fatigue.

The choice for an internet questionnaire was based on the advantages this method brings in term of speed and costs. Based on a comparison of a large internet sample and 500 traditional samples, Gosling et al. (2004) concluded that internet findings are consistent with findings from traditional methods and that these methods can contribute to many areas of psychology. However, the use of this method has been criticized due to (1) problems of internet coverage of the general population (Couper, 2000), (2) the difficulty of drawing probability samples (Couper, 2000), and (3) high nonresponse rates (Braunsberger et al., 2007).

In relation to the first, it can be noted that internet access in The Netherlands is among the highest in the world. In $200583 \%$ of the Dutch population had access to the internet (CBS, 2006), which suggests that the internet population accurately reflects the general population. However, usual differences found between the general population and the internet population, i.e., people with internet access are generally better educated, have higher incomes and are generally younger, have also been found in our sample (although this also might be due to the fact that, in general, these people are more motivated to participate in surveys). More specifically, a small overrepresentation exists of well-educated respondents and respondents with high incomes. However, the mean age of the respondents in the sample (mean standard deviation=49.8(14.5)) is not much different from (even higher than) the average age of the Dutch population of 18 years and older (mean $=46.7) .{ }^{6}$ In addition, since these 
variables are not strongly related to the main variable of interest, i.e., noise annoyance (see Table I), the bias present in the sample is considered to be negligible.

With respect to the second point of critique in relation to internet research, it can be noted that the usual problem of self-selection in web-based surveys, which prohibits generalizations in relation to a larger population, has been limited through the use of traditional methods for the sampling and recruitment of respondents. As mentioned earlier, a random sample was drawn from the survey area and respondents were approached via a letter that was delivered at their home address. In addition, the use of cookies prevented multiple entries from the same respondents.

This leaves the issue of nonresponse, which is of course also present in traditional postal or telephone surveys, unaddressed. Nonresponse is undesirable insofar there are main differences between the respondents and nonrespondents on the variables of interest. In this study, it is likely that annoyed people are more (than less annoyed people) inclined to participate. Based on the positive correlation found between the difference in the actual and expected response per municipality and the average noise annoyance score per municipality $(r=0.235, p=0.000)$, it can be concluded that the sample has indeed a small bias toward people who experience more noise annoyance than the average person living in the 45 DENL contour. However, since, to the authors' knowledge, previous empirical research has never indicated that the relation between nonacoustical factors and noise annoyance is different for varying degrees of noise annoyance, it is assumed that this small overrepresentation did not bias the estimated relationships between noise annoyance and other factors. Yet, this remains an issue of empirical investigation.

\section{B. Measurements}

Except for age, length of residence in noisy areas, concern about property devaluation, and noise exposure, the variables presented in Fig. 2 represent complex concepts that are considered to be latent variables. Latent variables are not measured by a single question in the questionnaire, but these are measured with multiple indicators. Noise annoyance and noise sensitivity were measured by previously validated scales. For noise annoyance, two standardized noise reaction items were used (Fields et al., 2001). Since three items per scale form a preferable minimum the scale was expanded with one item, which relates to annoyance due to disturbances. To measure noise sensitivity, the 21-item scale of Weinstein is used (Weinstein, 1978). Because of limited space in the questionnaire, a selection of ten items was included. It has been previously shown that this selection provides a reliable scale for noise sensitivity (Breugelmans et al., 2004). In addition, to increase the reliability of this scale, it is expanded with one general noise sensitivity question measured with an 11-point scale. All other scales are composed of newly formulated indicator variables, which are measured on seven-point Likert-type scales.

Normal procedure in structural equation modeling is to include all indicators of each latent variable into the structural equation model and thereby taking measurement error into account. However, to reduce the overall complexity of the model (i.e., the number of free parameters to be estimated) and since our interest lies in testing the structural part of the model, we constructed the different latent constructs $a$ priori by calculating sum scores of the multiple indicators and including only these summated scales as the indicators of the latent variables in the structural equation model. Following this procedure, the measurement error can still be taken into account (thereby retaining the benefits of a measurement model) if the measurement error of the summated scale is specified in the structural equation model. This is done by fixing the measurement error of the summated scales (the single indicator variable) at a value of 1 minus the Cronbach's alpha of the summated scale (Kelloway, 1998).

To that effect, the Cronbach's alpha of each summated scale was calculated in the statistical software package SPSS. By calculating the Cronbach's alpha, one assumes that the items represent a unidimensional scale, but the measure itself does not reveal whether this is the case or not. Therefore, factor analysis was conducted prior to calculating the Cronbach's alpha to check the unidimensionality of the each intended scale. Except for the construct "belief noise can be prevented," a single factor was found for each construct, implying that the summated scales are unidimensional. For the construct belief noise can be prevented, the item that has the highest correlation with the central variable, i.e., noise annoyance, is chosen as a single indicator to represent that latent variable. Furthermore, to ensure that each item sufficiently contributed to the measurement of the complex construct, only those items remained in the scale that had a factor loading larger than 0.50 . Table II presents an overview of the included scales and their respective items. Since no reliability value can be derived for the single item constructs belief noise can be prevented and "concern about property devaluation," these variables are assumed to be measured with the average reliability of all scales $(\alpha=0.83)$. All other constructs were represented by summated scale scores computed as the sum of the individual item scores.

\section{RESULTS}

The model tests and parameters estimates are based on the covariance matrix and used maximum likelihood estimation as implemented in Lisrel 8 (Jöreskog and Sörbom, 1992). ${ }^{7}$ After estimation of the full model in Fig. 2, the insignificant paths are deleted and the model is re-estimated. Insignificant paths can be considered irrelevant to the model and should, based on the parsimony criterion, be deleted from the model (Byrne, 1998). Hence all insignificant paths are fixed to zero. Variables that are left with no path are deleted from the model, after checking the modification indices to assess whether paths should be drawn that were not theoretically expected. These indices indicate the decrease in the chi-square value (i.e., improved fit) if an extra path between two factors is added. After this step, the following five factors are removed from the model as these have no significant relationships with other variables left: noise sensitivity, fear of noise source, personal dependency on the noise source, length of residence in noisy areas, and age. Hence, 
TABLE II. Overview of scales, Cronbach alpha's, items, and item ranges. Items with factors loadings smaller than 0.50 were removed from the solutions.

\begin{tabular}{|c|c|c|c|}
\hline Scale/latent variable & Alpha & Item & Range \\
\hline \multirow[t]{3}{*}{ Noise annoyance(past 12 months) } & \multirow[t]{3}{*}{0.89} & Level of annoyance due to air traffic 1 & $0=$ not annoyed at all $-10=$ very high annoyance \\
\hline & & Level of annoyance due to air traffic 2 & $1=$ not annoyed at all $-5=$ extremely annoyed \\
\hline & & Level of annoyance due to disturbances & $1=$ not annoyed at all $-7=$ very high annoyance \\
\hline \multirow{5}{*}{$\begin{array}{l}\text { Perceived disturbance } \\
\text { (past } 12 \text { months) }\end{array}$} & \multirow[t]{5}{*}{0.88} & Disturbances by aviation traffic during daytime & $1=$ never $-5=$ daily \\
\hline & & Disturbances by aviation traffic in sleep & $1=$ never $-5=$ daily \\
\hline & & Disturbances by aviation traffic during conversations & $1=$ never $-5=$ often \\
\hline & & $\begin{array}{l}\text { Disturbances by aviation traffic during activities that } \\
\text { demand concentration }\end{array}$ & $1=$ never $-5=$ often \\
\hline & & Disturbances by aviation traffic during resting & $1=$ never $-5=$ often \\
\hline \multirow[t]{2}{*}{$\begin{array}{l}\text { Negative expectations } \\
\text { toward noise development }\end{array}$} & \multirow[t]{2}{*}{0.83} & Belief personal noise situation will worsen & $\begin{array}{l}1=\text { noise situation will improve }-5=\text { noise } \\
\text { situation will deteriorate }\end{array}$ \\
\hline & & General belief noise exposure will increase & $\begin{array}{l}1=\text { noise level will decrease }-7=\text { noise level } \\
\text { will increase }\end{array}$ \\
\hline \multirow[t]{8}{*}{ Noise sensitivity } & \multirow[t]{8}{*}{0.86} & General noise sensitivity & $\begin{array}{l}0=\text { not at all noise sensitive }-10=\text { highly } \\
\text { noise sensitive }\end{array}$ \\
\hline & & I get used to most noises without much difficulty & $1=$ completely agree $-5=$ completely disagree \\
\hline & & $\begin{array}{l}\text { I am good at concentrating no matter what is going } \\
\text { on around me }\end{array}$ & $1=$ completely agree $-5=$ completely disagree \\
\hline & & I am easily awakened by noise & $1=$ completely agree $-5=$ completely disagree \\
\hline & & I find it hard to relax in a place that is noisy & $1=$ completely agree $-5=$ completely disagree \\
\hline & & I am sensitive to noise & $1=$ completely agree $-5=$ completely disagree \\
\hline & & Sometimes noises get on my nerves and get me irritated & $1=$ completely agree $-5=$ completely disagree \\
\hline & & I get angry with people making noise & $1=$ completely agree $-5=$ completely disagree \\
\hline \multirow[t]{2}{*}{ Fear of noise source } & \multirow[t]{2}{*}{0.76} & Fear of aircraft crash in neighborhood & $1=$ no fear at all $-7=$ extremely fearful \\
\hline & & Frightened when aircrafts fly over & $\begin{array}{l}1=\text { not frightened at all }-7=\text { extremely } \\
\text { frightened }\end{array}$ \\
\hline \multirow{3}{*}{$\begin{array}{l}\text { Positive social evaluation of } \\
\text { noise source }\end{array}$} & \multirow[t]{3}{*}{0.79} & I believe Schiphol is valuable for the region & $1=$ completely agree $-7=$ completely disagree \\
\hline & & I believe Schiphol is important for the Dutch economy & $1=$ completely agree $-7=$ completely disagree \\
\hline & & I believe flying is a sustainable transportation mode & $1=$ completely agree $-7=$ completely disagree \\
\hline \multirow{8}{*}{$\begin{array}{l}\text { Negative attitude toward } \\
\text { noise source authorities and } \\
\text { the noise policy }\end{array}$} & \multirow[t]{8}{*}{0.92} & $\begin{array}{l}\text { I believe Schiphol must be able to grow at its } \\
\text { current location }\end{array}$ & $1=$ completely agree $-7=$ completely disagree \\
\hline & & General attitude toward Schiphol & $1=$ very negative $-7=$ very positive \\
\hline & & Satisfaction with Schiphol policy, in general & $1=$ not satisfied at all $-7=$ extremely satisfied \\
\hline & & Belief Schiphol abuses its power & $1=$ no abuse at all $-7=a$ lot of abuse \\
\hline & & $\begin{array}{l}\text { I trust the government to maintain a good balance } \\
\text { betweenenvironmental and economic factors }\end{array}$ & $1=$ completely agree $-7=$ completely disagree \\
\hline & & I trust the government to uphold the environmental norms & $1=$ completely agree $-7=$ completely disagree \\
\hline & & I believe the government acknowledges the noise problem & $1=$ completely agree $-7=$ completely disagree \\
\hline & & Satisfaction with government policy on noise & $1=$ not satisfied at all $-7=$ extremely satisfied \\
\hline \multirow{4}{*}{$\begin{array}{l}\text { Concern about the negative } \\
\text { health effects of noise and } \\
\text { pollution }\end{array}$} & \multirow[t]{4}{*}{0.91} & Concern that pollution leads to negative health effects & $1=$ not concerned at all $-7=$ very much concerned \\
\hline & & Concern that noise leads to negative health effects & $1=$ not concerned at all $-7=$ very much concerned \\
\hline & & Concern that noise leads to sleep loss & $1=$ not concerned at all $-7=$ very much concerned \\
\hline & & Concern that noise leads to more stress & $1=$ not concerned at all $-7=$ very much concerned \\
\hline \multirow{3}{*}{$\begin{array}{l}\text { Annoyance related to } \\
\text { non-noise effects }\end{array}$} & \multirow[t]{3}{*}{0.85} & Annoyed by odour due to aircrafts & $1=$ not annoyed at all $-7=$ very much annoyed \\
\hline & & Annoyed by vibrations due to aircrafts & $1=$ not annoyed at all $-7=$ very much annoyed \\
\hline & & Annoyed by particles, dust or smoke due to aircrafts & $1=$ not annoyed at all $-7=$ very much annoyed \\
\hline \multirow{3}{*}{$\begin{array}{l}\text { Personal dependency on the } \\
\text { noise source }\end{array}$} & \multirow[t]{3}{*}{0.65} & Importance of Schiphol in relation to job & $1=$ not important at all $-7=$ very important \\
\hline & & Dependency on Schiphol due to travel needs & $1=$ not dependent at all $-7=$ very dependent \\
\hline & & Financial dependency on Schiphol & $1=$ not dependent at all $-7=$ very dependent \\
\hline \multirow[t]{3}{*}{$\begin{array}{l}\text { Perceived control and coping } \\
\text { capacity }\end{array}$} & \multirow[t]{3}{*}{0.77} & $\begin{array}{l}\text { Feeling of direct control (via physical measures) } \\
\text { over the experienced level of noise exposure }\end{array}$ & $1=$ no control at all $-7=$ very much control \\
\hline & & $\begin{array}{l}\text { Feeling of being powerless in relation to the noise } \\
\text { situation }\end{array}$ & $1=$ very powerless $-7=$ not powerless at all \\
\hline & & Capacity to deal with aircraft noise & $1=$ very low capacity $-7=$ very high capacity \\
\hline
\end{tabular}




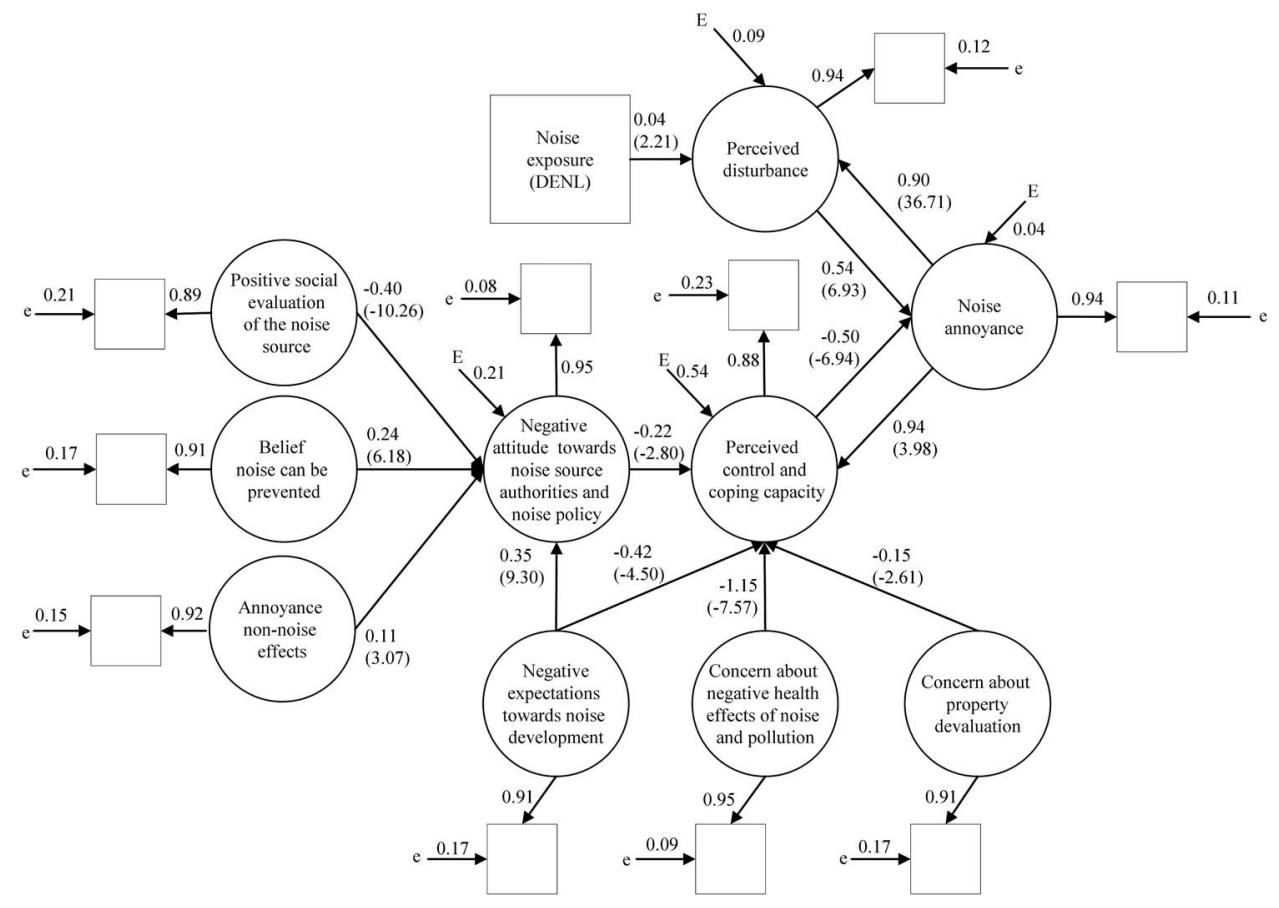

FIG. 3. The estimated aircraft noise annoyance model. $n=646, \chi^{2}=54.45$, $p$-value $=0.00008, D f=21, \mathrm{GFI}=0.99$, $\mathrm{CFI}=1.00$, and RMSEA $=0.044$. The standardized path estimates are shown. The values in the parentheses represent the $t$-values of the structural parameter estimates. All parameter estimates are significant $(p<0.05)$. $(\bigcirc)$ Latent variable; $(E)$ error/unexplained variance of latent variable; $(\square)$ observed variable (based on single-item composite scale); (e) error/ unexplained variance of observed variable.

taking into account the other variables that are still in the model, these variables are unable to explain additional variance in the endogenous variables. Figure 3 presents the final model.

The chi-square value is statistically significant $\left(\chi^{2}\right.$ $=54.45, p=0.00008$ ), which means that the model implied covariance matrix is significantly different from the observed covariance matrix. However, since this statistic is very sensitive for large sample sizes $(N>500)$, the review of other fit indices is recommended (Browne and Cudeck, 1993; Hu and Bentler, 1995; Schermelleh-Engel et al., 2003). The values for the goodness-of-fit index (GFI) and the comparative fit index (CFI) are well above the recommended lower limit of 0.90 , which suggests a good model fit. The root mean square error of approximation (RMSEA), a badness-of-fit index, has a value below the recommended upper limit of 0.05 , which again suggests a good model fit. Overall, it can be concluded that the model fit is good. In addition, all the signs of the hypothesised relationships between the variables are as expected.

The values related to each path in Fig. 3 represent the standardized parameter estimates. Standardization of the estimates makes comparisons in terms of the relative importance of each path possible. It can be concluded that the effect sizes of perceived disturbance and perceived control and coping capacity on noise annoyance, 0.54 and -0.50 , respectively, are quite similar. The effects of noise annoyance on perceived disturbance and perceived control and coping capacity, 0.90 and 0.94 , respectively, are also of the same magnitude. It can be concluded that to a large extent, the reciprocal effects between noise annoyance and perceived disturbance and noise annoyance and perceived control and coping capacity cancel each other out.

The only significant determinant of perceived disturbance is the level of noise exposure. However, the effect size of 0.04 can be qualified as small. The significant determi- nants of the perceived level of control and coping capacity are the negative attitude toward noise source authorities and the noise policy $(-0.22)$, the negative expectations related to noise development $(-0.42)$, the concern about negative health effects of noise and pollution $(-1.15)$, and the concern about property devaluation $(-0.15)$. Especially, the concern about negative health effects has a large effect on the capacity of people to handle the noise situation.

The positive social evaluation of noise source $(-0.40)$, the belief that noise can be prevented (0.24), and annoyance related to non-noise effects $(0.11)$ influence the negative attitude toward noise source authorities and the noise policy. The most important determinant of this factor is the positive social evaluation.

Only the negative expectation related to the future noise development has both a direct $(-0.42)$ and an indirect effect $\left(0.35^{*}-0.22=-0.077\right)$ on the perceived level of control and coping capacity. The presence of both effects is theoretically plausible. The indirect effect, via the negative attitude toward source authorities, can be explained by the mechanism that, if the belief exists that the noise situation will worsen, the noise source authorities are to blame for the expected increase in noise, which negatively influences the attitude toward the authorities. The direct effect, on the other hand, can be explained by the mechanism that a negative expectation related to the future noise development creates an immediate sense of despair (i.e., expecting that the situation will be become worse makes the appreciation of the current situation worse).

In order to assess the total effect of each variable on the central variable noise annoyance, the standardized total effects need to be assessed. These are presented in Table III.

The total effect of a variable is the combination of the indirect and direct effects. It can be concluded that the concern about negative health effects of noise and pollution, the 
TABLE III. Standardized total effects of each variable on noise annoyance.

\begin{tabular}{lc}
\hline \hline Variable & Effect \\
\hline Concern about negative health effects of noise and & 0.59 \\
pollution & \\
Perceived disturbance & 0.56 \\
Perceived control and coping capacity & -0.51 \\
Negative expectations toward noise development & 0.26 \\
Negative attitude toward source authorities & 0.11 \\
Concern about property devaluation & 0.08 \\
Positive social evaluation of the noise source & -0.05 \\
Belief noise can be prevented & 0.03 \\
Noise annoyance & 0.02 \\
Noise exposure (DENL) & 0.02 \\
Annoyance non-noise effects & 0.01 \\
\hline \hline
\end{tabular}

perceived disturbance, and the perceived control and coping capacity are the most important determinants of noise annoyance. Noise annoyance (via the reciprocal relationships), noise exposure, and annoyance non-noise effects have the lowest total effects on noise annoyance.

The error terms of the latent constructs (i.e., the E's in Fig. 3) indicate the proportions of unexplained variance of the endogenous variables. Since the model is nonrecursive (i.e., it includes feedback loops), the interpretation of the proportion of explained variance $\left(1-E\right.$ or $\left.R^{2}\right)$ is not the same as it would be in traditional regression analysis (Jöreskog, 2000). This interpretation only holds for the negative attitude toward source authorities and the noise policy. Jöreskog (2000), therefore, advised assessing the $R^{2}$ 's calculated from the reduced form equations, which indicate the proportions of variance in the endogenous variables solely explained by the exogenous variables. For each endogenous variable, the $R^{2}$ of the reduced form is presented in Table IV.

Even though the unique portions of variance explained by the endogenous variables in each other are not included, the $R^{2}$ values are still high. In addition, the explained variance in noise annoyance, $78 \%$, is considerably higher than in a path model previously estimated on this topic, which was able to explain $42 \%$ in noise annoyance (Taylor, 1984).

\section{CONCLUSION AND DISCUSSION}

In this study, a structural equation model is developed and estimated to explain aircraft noise annoyance. In contrast to existing models that largely lack a sound theoretical basis, the model presented in this paper is theoretically well founded. As a result, the model provides a better insight into the factors and causal processes that precede and result in aircraft noise annoyance. In addition, the use of SEM to

TABLE IV. The proportions of explained variance in the endogenous variables $\left(R^{2}\right.$ 's) based on the reduced form equations.

\begin{tabular}{ll}
\hline \hline Endogenous variable & $R^{2}$ \\
\hline Noise annoyance & 0.78 \\
Perceived disturbance & 0.65 \\
Perceived control and coping capacity & 0.79 \\
Negative attitude toward source authorities & 0.79 \\
\hline \hline
\end{tabular}

model and explain noise annoyance has proven itself to be a suitable method in overcoming the shortcomings of previously used methods such as correlational analysis and multiple regression analysis. The final model provides a good model fit and supports the presence of indirect and reciprocal effects, which empirically have not previously been identified. It can be concluded that the concern about the negative health effects of noise and pollution, the level of perceived disturbance, and the level of perceived control and coping capacity have the highest total effects on noise annoyance. Finally, the proportion of explained variance in noise annoyance is higher than in previous models.

Controlled for other variables still in the model, the variables noise sensitivity, fear related to the noise source, personal dependency on the noise source, length of residence in noisy areas, and age have no significant relationships with endogenous variables in the model and were therefore excluded from the model. The exclusion of the variables noise sensitivity and fear in relation to the noise source is especially remarkable, since many studies emphasise the importance of these factors (e.g., see Fields, 1993; Van de Kamp et al., 2004; Miedema and Vos, 1999). Although these variables show significant correlations with noise annoyance, 0.51 and 0.50 , respectively, they are unable to explain additional variance given the other variables still in the model. With respect to the exclusion of fear related to the noise source, a probable explanation is that the concern about the negative health effects of noise and pollution explains the same variance in the perceived control and coping capacity variable. This explanation seems reasonable since a fairly strong correlation between fear related to the noise source and concern about negative health effects of noise and pollution exists $(r$ $=0.54, p=0.000$ ). An explanation of a similar form can be found for the exclusion of noise sensitivity. The variable perceived control and coping capacity show a significant correlation with noise sensitivity $(r=-0.48, p=0.000)$, and its influence in the model is the probable cause for the suppression of the effect of noise sensitivity. However, as opposed to the relation between fear and the concern about negative health effects, we cannot identify a theoretical explanation why noise sensitivity and perceived control and coping capacity are empirically associated. Based on this finding, we recommend future research to address this particular relationship and the theoretical mechanism that underlies it, as well as, from a more general perspective, the relationship between noise sensitivity and other nonacoustical factors.

In relation to this study, some reflective remarks and related recommended directions for further research can be made. The first remark and associated research direction is related to the theoretical framework, developed by Stallen (1999), on which our causal model is based. Based on this theoretical framework, the specified model structure presented in this paper is deemed the most plausible one. The fact that the model is not falsified, however, does not exclude the validity of other theoretical frameworks. With respect to the apparent lack of theoretical insights in the phenomenon noise annoyance, we stress that future research related to the acoustical and nonacoustical antecedents of noise annoyance 
should focus on the fundamental causal mechanisms that exist between variables, in addition to finding statistically significant associations between them. Rich qualitative descriptions related to the causal mechanisms "at work" between variables can be used to verify or falsify the used model structure or can be used to develop a new theoretical framework and related model structure(s). Since these descriptions cannot be derived from current theoretical insights or from traditional quantitative approaches, other means to derive these will have to be explored. A qualitative research approach (e.g., using in-depth interview techniques) is considered to be suitable in this respect.

A second remark and associated research opportunity, which partly overlaps with the previous one, relates to the assumed temporal causal order between variables. The estimated relationships in the model depicted in Fig. 3 are based on the assumption that the identified causes (independent variables) precede the effects (dependent variables) in time. However, as opposed to other causal models, the assumption of time precedence in our aircraft noise annoyance model is questionable. All the variables in the model, except noise exposure, constitute concepts such as beliefs, attitudes, perceptions, expectations, and evaluations. These types of variables are by nature very abstract. Although a causal ordering can be assumed based on theoretical notions (e.g., a general belief precedes a specific attitude), this assumption cannot be empirically investigated. The reason for this is that the model is based on cross-sectional data. Inferences based on this model about the temporal order between variables and the directions of causation are therefore inherently less strong. This is especially true for the estimated reciprocal relationships (i.e., does perceived control and coping capacity cause noise annoyance, vice versa, or does indeed a reciprocal relationship exist?). Hence, with respect to our developed aircraft noise annoyance model as well as future models to explain noise annoyance, special attention to the tenability of the assumption of time precedence is justified. A suitable approach to empirically investigate the tenability of the timeprecedence criterion is through the use of panel data. More specifically, a SEM panel design can yield empirical evidence of a specific causal ordering between two variables (Finkel, 1995). ${ }^{8}$

A third direction for further research is to apply the model to residents around other airports in varying countries and explore similarities and differences between them. It should be taken into account that country or airport specific variables can play a role. These variables can be related to cultural characteristics of the country or to the specific policy context of the airport. For example, the qualitative research Bröer (2006) shows that the policy discourse at an airport influences the meaning people attribute to the sound of aircrafts. This, in turn, influences their experienced level of annoyance. In addition, through cross-national comparative research "best practices" of (nonacoustical) sound management can be identified.

The last research direction is related to the inclusion of acoustical and situational factors (e.g., frequency, tone, impulsiveness, time of day, the presence of noise insulation, arrangement of rooms and home type, and background noise level). The model in this study included only a year's mean noise exposure metric (DENL). The limited range of this metric (i.e., 45-58 DENL) has likely contributed to the relatively low effect of this variable in the estimated model (see also Job, 1988). The assessment of the influence of noise exposure can be improved by taking into account a larger geographical area for sample selection (to include levels below 45 DENL) and by oversampling (and subsequent weighting) of residents with high exposure levels (above 58 DENL). Especially in the case of AAS, oversampling is necessary since a relatively small proportion of the total population is exposed to these high levels of noise exposure. In addition, the assessment can possibly be improved through the inclusion of noise descriptors based on other weighting filters (e.g., C-weighting) or a dynamic filter (Schomer, 2001). Lastly, to estimate the relative importance of other acoustical and situational variables, we recommend inclusion of these factors in future models of aircraft noise annoyance.

To conclude, we believe that insights into the preceding factors and causal processes of aircraft noise annoyance open the door for revision of existing policies and the design of new policies to reduce this adverse effect. Treating aircraft noise annoyance around airports as a mere technical problem, involving exposure levels and dose-response functions is only one side of addressing the noise problem.

\section{ACKNOWLEDGMENTS}

The authors wish to thank two anonymous reviewers for their useful comments and suggestions on an earlier draft of this paper.

\footnotetext{
${ }^{1}$ Different metrics exist to indicate the level of noise exposure (e.g., energybased indices and number of events). A study of Vincent et al. (2000) revealed that correlations between these different noise exposure metrics and noise annoyance are both low $(r \sim 0.30)$ and very similar. Hence, it can be concluded that noise level descriptors, in general, are unable to explain individual levels of noise annoyance.

${ }^{2}$ DENL (day-evening-night level) is an equivalent sound level of $24 \mathrm{~h}$ expressed in decibels on the "A" weighted scale $\mathrm{dB}(\mathrm{A})$, which, in this study, is calculated for the period of a year. Sound levels during the evening (7 pm-11 pm) and during the night (11 pm-7 am) are increased by penalties of 5 and $10 \mathrm{~dB}(\mathrm{~A})$, respectively. This metric is selected by the European Council to monitor and assess noise problems in its member states. It needs to be noted, however, that this metric has been criticized for its use to assess environmental noise because A-weighting approximates the response characteristics of the human ear only for narrow band sounds at low levels. It has been shown to underestimate the effects of lowfrequency noise on pleasantness and annoyance ratings (e.g., Schomer et al., 2001). In addition, broad band sounds such as aircraft noises are underestimated by A-weighting with respect to their loudness and annoyance by typically $15 \mathrm{~dB}$.

${ }^{3}$ However, this also means that in situations where drastic changes in exogenous factors take place, our model cannot be used.

${ }^{4}$ Glass and Singer (1972) (p. 10) also note that "continued exposure to a stressor may produce cumulative effects that appear only after stimulation is terminated; it is as though the organism does not experience maximal stress until he is no longer required to cope with the stressor." Since this effect only incurs after the stressful situation has passed, it is not included in our causal model.

${ }^{5}$ For every respondent in the sample, the level of noise exposure (a year mean DENL) was calculated by the National Aerospace Laboratory (NLR). This was done by transforming the four-digit two-letter postal code of each respondent's residence, which includes on average an area of $50 \mathrm{~m}^{2}$ (approximately 15 households) (Batty et al., 2004), into $X Y$-coordinates, which are subsequently used to determine the level of
} 
noise exposure at the particular location. Calculations for the level of noise exposure are based on the 12 month period before the execution of the survey (the period from May 2005 to April 2006).

${ }^{6}$ Ideally, the sample should be compared to the chosen population (i.e., all residents within the 45 DENL contour). However, since no demographic information was available for this population, the sample was compared to the Dutch population of 18 years and above.

${ }^{7}$ With respect to the developed causal model in Fig. 2, two theoretical uncertainties were identified. Since the ultimate objective was to develop a model that is both theoretically meaningful and statistically well fitting, these two theoretical uncertainties were combined in four alternative model specifications, which all represented plausible views on reality. To find the model that was "most plausible," all four models were estimated and compared. In comparison to the other models, the model discussed in this paper, which is presented in Fig. 2, provided the best fit to the data and was therefore assumed to reflect the most plausible view on reality. To be able to present a concise paper, the choice was made not to include the discussion of these alternative models nor their results. These can, however, be requested in correspondence with the authors.

${ }^{8}$ Within a SEM panel design, the effect of an independent variable $X_{0}$ (read: $X$ at time point 0 ) on a dependent variable $Y_{1}$ is controlled for $Y$ 's own stability. Hence, if $X_{0}$ is able to explain variation in $Y_{1}$, over and above the variation $Y_{0}$ can explain in $Y_{1}$ (the stability of $Y$ ), it can be empirically inferred that $X$ is a causal predictor of $Y$.

Alexandre, A. (1976). "An assessment of certain causal models used in surveys on aircraft noise annoyance," J. Sound Vib. 44, 119-125.

Batty, M., Besussi, E., Maat, K., and Harts, J. J. (2004). "Representing multifunctional cities: density and diversity in space and time," Build. Environ. 30, 324-337.

Bollen, K. A. (1989). Structural Equations with Latent Variables (Wiley, New York).

Braunsberger, K., Wybenga, H., and Gates, R. (2007). "A comparison of reliability between telephone and web-based surveys," J. Bus. Res. 60, $758-764$.

Breugelmans, O. R. P., Van Wiechen, C. M. A. G., Van Kamp, I., Heisterkamp, S. H., and Houthuijs, D. J. M. (2004). "Gezondheid en beleving van de omgevingskwaliteit in de regio Schiphol: 2002 ("Health and the perception of environmental quality in the Schiphol area")," Bilthoven, The Netherlands.

Bröer, C. (2006). Beleid vormt overlast (Policy frames annoyance) (Aksant, Amsterdam).

Browne, M. W., and Cudeck, R. (1993). in Testing Structural Equations Models, edited by K. A. Bollen and J. S. Long (Sage, Newbury Park), pp. 136-162.

Byrne, B. M. (1998). Structural Equations Modeling with Lisrel, Prelis and Simplis: Basic Concepts, Applications and Programming (LEA, London).

Central Bureau of Statistics (CBS) (2006). "E-mailen en chatten populairste internetactiviteiten ("E-mail and chatting are the most popular internet activities")," by G. Linden, CBS Webmagazine, Voorburg, The Netherlands.

Couper, M. P. (2000). "Web surveys: a review of issues and approaches," Public Opin. Q. 64, 464-494.

Fields, J. M. (1993). "Effect of personal and situational variables on noise annoyance in residential areas," J. Acoust. Soc. Am. 46, 2753-2763.

Fields, J. M., de Jong, R. G., Gjestland, T., Flindell, I. H., Job, R. F. S., Kurra, S., Lercher, P., Vallet, M., Yano, T., Guski, R., and Schumer, R. (2001). "Standardised general-purpose noise reaction questions for community noise surveys: research and a recommendation community response to noise team of ICBEN (the International Commission on the Biological Effects of Noise)," J. Sound Vib. 242, 641-679.

Finkel, S. E. (1995). Causal Analysis with Panel Data (Thousand Oaks, London).
Friedman, M., and Rosenman, R. H. (1974). Type A behavior and Your Heart (Knopf, New York).

Glass, D. C., and Singer, J. E. (1972). Urban Stress. Experiments on Noise and Social Stressors (Academic, New York).

Gosling, S. D., Vazire, S., Srivastava, S., and John, O. P. (2004). "Should we trust web-based studies?: A comparative analysis of six preconceptions about internet questionnaires," Am. Psychol. 59, 93-104.

Guski, R. (1999). "Personal and social variables as co-determinants of noise annoyance," Noise Health 1, 45-56.

Guski, R., Felscher-Suhr, U., and Scheuemer, R. (1999). "The concept of noise annoyance: how international experts see it," J. Sound Vib. 223, 513-527.

Hu, L., and Bentler, P. M. (1995). in Structural Equation Modeling: Concepts, Issues, and Applications, edited by R. H. Hoyle (Sage, Thousand Oaks, CA), pp. 76-99.

Job, R. F. S. (1988). "Community response to noise: A review of factors influencing the relationship between noise exposure and reaction," J. Acoust. Soc. Am. 83, 991-1001.

Job, R. F. S. (1996). "The influence of subjective reactions to noise on health effects of the noise," Environ. Int. 22, 93-104.

Jöreskog, K. G. (2000). The interpretation of $R^{2}$ revisited. Retrieved 12 July 2007 from http://www.ssicentral.com/lisrel/techdocs/r2rev.pdf.

Jöreskog, K. G., and Sörbom, D. (1992). LISREL VIII: Analysis of Linear Structural Relations (Scientific Software, Mooresville).

Kelloway, E. K. (1998). Using Lisrel for Structural Equations Modeling, A Researcher's Guide (Sage, California).

Lazarus, R. S. (1966). Psychological Stress and the Coping Process (McGraw-Hill, New York).

Lercher, P. (1996). "Environmental noise and health: an integrated research perspective," Environ. Int. 22, 117-129.

Maris, E., Stallen, P. J., Vermunt, R., and Steensma, H. (2007). "Noise within the social context: annoyance reduction through fair procedures," J. Acoust. Soc. Am. 121, 2000-2010.

Miedema, H. M. E., and Vos, H. (1998). "Exposure-response relationships for transportation noise," J. Acoust. Soc. Am. 104, 3432-3445.

Miedema, H. M. E., and Vos, H. (1999). "Demographic and attitudinal factors that modify annoyance from transportation noise," J. Acoust. Soc. Am. 105, 3336-3344.

RIVM and RIGO (2006). "Evaluatie Schipholbeleid. Schiphol beleefd door omwonenden ("Policy evaluation Schiphol: Schiphol experienced by residents")," Bilthoven, The Netherlands.

Schermelleh-Engel, K., Moosbrugger, H., and Müller, H. (2003). "Evaluating the fit of structural equation models: Tests of significance and descriptive goodness-of-fit measures," MPR-online 8, 23-74.

Schomer, P. D., Suzuki, Y., and Saito, F. (2001). "Evaluation of loudnesslevel weightings for assessing the annoyance of environmental noise," J. Acoust. Soc. Am. 110, 2390-2397.

Stallen, P. J. M. (1999). "A theoretical framework for environmental noise annoyance," Noise Health 1, 69-80.

Taylor, S. M. (1984). "A path model of aircraft noise annoyance?" J. Sound Vib. 96, 243-260.

Van Eeten, M. J. G. (2001). "Recasting intractable policy issues: The wider implications of The Netherlands civil aviation controversy," J. Policy Anal. Manage. 20, 391-414.

Van Kamp, I., Job, R. F. S., Hatfield, J., Haines, M., Stellato, R. K., and Stansfeld, S. A. (2004). "The role of noise sensitivity in the noise-response relation: A comparison of three international airport studies," J. Acoust. Soc. Am. 116, 3471-3479.

Vincent, B., Vallet, M., Olivier, D., and Paque, G. (2000). "Evaluation of variations of the annoyance due to aircraft noise," Internoise 2000, Nice, France, 27-30 August.

Weinstein, N. D. (1978). "Individual differences in reactions to noise: A longitudinal study in a college dormitory," J. Appl. Psychol. 63, 458-566. 